\title{
Epidemiological Findings of Refractive Errors and Amblyopia among the Schoolchildren in Hatta Region of the United Arab Emirates
}

\author{
Salam Chettian Kandia, b Hayat Ahmad Khan ${ }^{a}$

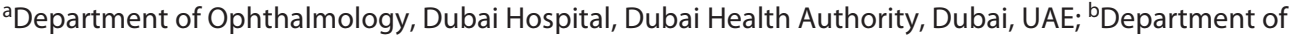 \\ Ophthalmology, Hatta Hospital, Dubai Health Authority, Dubai, UAE
}

\section{Keywords}

Amblyopia $\cdot$ Pediatric ophthalmology $\cdot$ Refractive error .

School-going children · Vision

\begin{abstract}
Introduction: Uncorrected refractive errors and amblyopia pose a major problem affecting schoolchildren. We had previously observed that many schoolchildren in the Hatta region presented to the ophthalmology clinic with uncorrected refractive errors and amblyopia, which led us to undertake this research. As per the WHO, the term "visual impairment" can be "low vision" or "blindness." Based on the presenting vision, "low vision" is defined for children who have vision of $<6 / 18$ to $3 / 60$ or having visual field loss to $<20^{\circ}$ in the better-seeing eye. Children defined to have "blindness" have presenting vision of $<3 / 60$ or corresponding visual field of $<10^{\circ}$. Purpose: To estimate the magnitude of uncorrected refractive errors and amblyopia among the schoolchildren aged 6-19 years and to assess the efficacy of school-based refractive error screening programs in the Hatta region of the United Arab Emirates. Methods: An epidemiological, cross-sectional, descriptive study was conducted on the entire student population studying in the government schools of the region. Those who failed the Snellen visual acuity chart test and those who were wearing spectacles
\end{abstract}

were evaluated comprehensively by the researcher in the Department of Ophthalmology of the Hatta Hospital. Data were entered in the Refractive Error Study in School Children (RESC) eye examination form recommended by the WHO, and were later transferred to Excel sheets and analyzed by SPSS. Results: 1,591 students were screened and evaluated from the end of 2016 to mid-2017. About $21.37 \%(n=340)$ had impaired vision with $20.9 \%(n=333)$ refractive errors, of which $58 \%$ were uncorrected. Among the refractive error group, 19\% (64 subjects) had amblyopia (4\% of total students). The incidence of low vision was $9.5 \%$ and blindness was $0.38 \%$. Low vision was found to be $9.5 \%$ and blindness $0.38 \%$, taking in to account presenting visual acuity rather than best-corrected visual acuity for defining low vision and blindness. Conclusion: A significant number of students were detected to have uncorrected refractive errors among the vision impaired group $(59 \%, n=197)$ despite a schoolbased vision screening program in place. Seventy-eight percent of the amblyopia cases $(n=50)$ were found to be in the 11-19 years age group. Noncompliance with optical corrections was the reason for the high number of cases. A rigorous vision screening program and refractive services, complimented with awareness among parents and teachers, are recommended.

(c) 2021 The Author(s)

Published by S. Karger AG, Basel karger@karger.com www.karger.com/dmj

Karger $\stackrel{\text { ' }}{5}$

GOPEN ACCESS
(C) 2021 The Author(s)

Published by S. Karger AG, Basel

This article is licensed under the Creative Commons AttributionNonCommercial-NoDerivatives 4.0 International License (CC BYNC-ND) (http://www.karger.com/Services/OpenAccessLicense). Usage and distribution for commercial purposes as well as any distribution of modified material requires written permission.
Hayat Ahmad Khan

Department of Ophthalmology, Dubai Hospital Dubai Health Authority, Al Khaleej Street, Al Baraha Dubai 7272 (UAE) hayatkhan@dha.gov.ae 


\section{Introduction}

Blindness and visual impairment constitute a major health problem and an economic burden across the globe. According to VISION 2020: the "Right to Sight Initiative" of the World Health Organization (WHO), childhood blindness is part of a global endeavor to fight blindness [1].

A review of literature indicates that the burden of visual impairment across the globe amounts to 285 million people, of which $80 \%$ are avoidable or curable. Two major components $(66 \%)$ of these preventable or curable causes are refractive errors and cataract [2]. The WHO Global Action Plan 2014-2019 emphasizes the need to generate data on the prevalence of avoidable blindness and to reduce this by $25 \%$ by the year 2019 .

The latest global estimate of visual impairment suggests that among children aged 5-15 years, 12.8 million were visually impaired due to refractive errors, representing a prevalence of $0.97 \%$, with higher prevalence reported in China and urban areas of Southeastern Asia [3].

Children with visual impairment that remains uncorrected fall behind in terms of academic achievement, personal development, social skills, and self-esteem. Poor vision and an inability to read materials on the chalkboard due to refractive error can profoundly affect a child's participation and learning in the classroom [3]. It also has serious social implications for the child in the school [4]. Importantly, among the causes of poor performance in schoolchildren, refractive errors rank first [5]. This array of problems means that these children could face avoidable social, educational, and economic problems such as unemployment, lower level of education, and training and possible psychological problems due to their childhood lack of confidence and self-respect during adulthood. Furthermore, amblyopia in schoolchildren poses a greater challenge as if it is not addressed early, treatment will not be beneficial $[6,7]$.

In the Hatta region, despite having a good schoolbased screening process and access to health care facilities, numerous children present to the Department of Ophthalmology of the Hatta Hospital with uncorrected refractive errors and amblyopia at an older age.

In the United Arab Emirates, no summary of evidence has been published about the prevalence of uncorrected refractive errors and amblyopia among children in schools. Therefore, the aim of this study was to determine the prevalence of uncorrected refractive errors and amblyopia and to select suitable mechanism to improve students' vision by recommending effective screening processes.

\section{Methodology}

\section{Study Setting and Demographics}

According to the 2016 census, the estimated population was 12,200 in Hatta, which is an exclave of Dubai, United Arab Emirates [8]. It is $105 \mathrm{~km}$ away from Dubai city, bordering Oman. Entire enrolled students of the age group of 6-19 years in all the 4 government schools of the region were screened. The schools are Hatta School for junior boys, Rashid School for senior boys, Khadija School for junior girls, and Dhahra School for senior girls. During the study period, the total population of all 4 schools was 1,591 students.

Before commencing the research project, Dubai Research and Ethics Committee's permission was obtained. In addition, permission was also obtained from the CEO of the Hatta Hospital and principals of all 4 schools. A consent form was distributed, and parents were made aware of the intended study. The World Medical Association (WMA) Declaration of Helsinki was adhered to, throughout the study period.

This study had 2 sections. First, the initial vision screening was carried out in the schools. Second, a comprehensive examination for those who failed the vision test was carried out in the Department of Ophthalmology of the Hatta Hospital. A team of an ophthalmologist and an optometrist visited the schools and was satisfied with the visual acuity screening rooms and the skill of the inhouse nurses conducting the test. Initial screening was carried out in schools by the nurse under the supervision of the optometrist, and visual acuity was tested at $6 \mathrm{~m}$ using Snellen E chart. Screening continued in all 4 schools for a period of 3 months. A list of students who failed the Snellen E chart test and those who were wearing glasses were prepared, and they were scheduled to attend the ophthalmology clinic of the Hatta Hospital, where a detailed ophthalmic evaluation was carried out. This was done over a period of 4 months. For these children, the Refractive Error Study in School Children (RESC) guidelines and forms were used, and cycloplegic refraction using $1 \%$ cyclopentolate was performed in all cases. Presenting visual acuity, unaided visual acuity, and best-corrected visual acuity were recorded by optometrist. In addition, an ocular motility examination, slit lamp examination, and fundus examination were carried out in all cases by the ophthalmologist. RESC form was filled for each child examined in the clinic after assigning a specific code for each school, grade, division, and roll number of the student. Accuracy and completeness of the filled forms were checked by the researcher ophthalmologist. Required data from the forms were transferred to Excel sheets. All members of the research team contributed to developing the final interpretation.

\section{Data Analysis}

Myopia was considered when the refractive error was $\geq-0.5$ diopter in one or either eye, astigmatism when the refractive error was $\geq-0.5$ diopter cylinder, and hypermetropia when the refractive error was $\geq+2.0$ diopters. As per the American Academy of Ophthalmology, amblyopia is defined as loss of vision in one or both eyes caused by conditions that impair the normal visual input during the period of development of vision. For this study, we categorized amblyopia children having a best-corrected visual acuity of $\leq 6 / 12$ in one or both eyes without any other ocular pathology. Low vision is defined as a visual acuity of $6 / 18-3 / 60$ in the bestseeing eye and blindness as $<3 / 60$ in the best-seeing eye, taking in to account presenting visual acuity rather than best-corrected vi- 
Table 1. Distribution of 4 variables - enumerated, with visual impairment, and fully evaluated

\begin{tabular}{|c|c|c|c|c|c|c|}
\hline \multirow[t]{2}{*}{ Age } & \multicolumn{2}{|c|}{$\begin{array}{l}\text { Enumerated, } \\
n(\%)\end{array}$} & \multicolumn{2}{|c|}{$\begin{array}{l}\text { With visual impairment, } \\
n(\%)\end{array}$} & \multicolumn{2}{|c|}{$\begin{array}{l}\text { Fully evaluated (refractive } \\
\text { errors), } n(\%)\end{array}$} \\
\hline & male & female & male & female & male & female \\
\hline $6-10$ years & $411(25.8)$ & $322(20.2)$ & 77 (4.8) & $29(1.7)$ & 75 (4.7) & $29(1.7)$ \\
\hline $11-19$ years & $424(26.6)$ & $434(27.2)$ & $107(6.7)$ & $127(7.9)$ & $102(6.5)$ & $127(7.9)$ \\
\hline \multirow[t]{2}{*}{ Total } & $835(52.4)$ & $756(47.5)$ & $184(11.6)$ & $156(9.7)$ & $177(11)$ & $156(9.7)$ \\
\hline & \multicolumn{2}{|c|}{$1,591(100)$} & \multicolumn{2}{|c|}{$340(21.37)$} & \multicolumn{2}{|c|}{333 (20.9) } \\
\hline
\end{tabular}

Table 2. Distribution of refractive errors by gender, age group, and wearing or not wearing spectacles

\begin{tabular}{|c|c|c|c|c|c|}
\hline & \multicolumn{2}{|l|}{ Male } & \multicolumn{2}{|l|}{ Female } & \multirow[t]{2}{*}{ Total, $n(\%)$} \\
\hline & $6-10$ years & $11-19$ years & $6-10$ years & $11-19$ years & \\
\hline Total number of children screened & 411 & 424 & 322 & 434 & $1,591(100)$ \\
\hline Normal & 334 & 317 & 293 & 307 & $1,251(78.6)$ \\
\hline \multicolumn{6}{|l|}{ Vision impaired (etiology) } \\
\hline Hypermetropia & 12 & 7 & 4 & 6 & $29(1.8)$ \\
\hline Myopia & 25 & 59 & 13 & 98 & $195(12.25)$ \\
\hline Astigmatism & 38 & 36 & 12 & 23 & $109(6.85)$ \\
\hline Underdetermined & 2 & 5 & 0 & 0 & $7(0.43)$ \\
\hline Total (vision impaired) & 77 & 107 & 29 & 127 & $340(21.4)$ \\
\hline \multicolumn{6}{|c|}{ Spectacle usage among vision impaired $(N=340)$} \\
\hline \multicolumn{6}{|c|}{ Vision impaired (spectacle usage) } \\
\hline Wearing spectacles & 19 & 36 & 7 & 82 & $143(42)$ \\
\hline Not wearing spectacles & 58 & 71 & 22 & 45 & $197(58)$ \\
\hline Total (vision impaired) & 77 & 107 & 29 & 127 & $340(100)$ \\
\hline
\end{tabular}

sual acuity for defining low vision and blindness [9-12]. Being a cross-sectional study and all data being nominal categorical, we analyzed the data as frequencies and percentages. Microsoft Excel 2013 and SPSS version 20 were used for data analysis.

\section{Results}

During the study period all the 4 government schools in the region had a student population of 1,591 , of which $756(47.5 \%)$ were girls and 835 (52.5\%) were boys. Out of the 835 boys, $411(49.2 \%)$ were in the $6-10$ years age group and 424 (50.8\%) were in the 11-19 years age group. In the girls group, there was 322 in the $6-10$ years age group and 434 in the 11-19 years age group, as shown in Table 1. All the students were enumerated, and $100 \%$ screening was achieved as the screening process spanned over a period of 3 months. Out of 1,591 children, 340 (21.37\%) had visual impairment, of which 333 had come for a complete evaluation in the hospital, which is $98 \%$ of the vision impaired group. Only 7 children $(<1 \%)$ did not turn up for evaluation in the hospital.

Refractive error was analyzed after performing a cycloplegic refraction and a post-mydriatic test with subjective correction in all the vision impaired group. Table 2 shows that $29(1.8 \%)$ students have hyperopia, 195 (12.25\%) students have myopia and 109 (6.85\%) have astigmatism, totaling 333 students with refractive error, which is $20.9 \%$ of the total students under study. Within the refractive error group of the 333 students, myopia ranks first with 195 (58.5\%) students, followed by astigmatism in 109 (32.73\%) and hyperopia in 29 (8.7\%).

The frequency distribution of refractive errors by age and gender is shown in Figure 1. A steady increase in myopia can be observed in both girls and boys as the age increases. The significant increase in myopia with age is more pronounced in girls. 


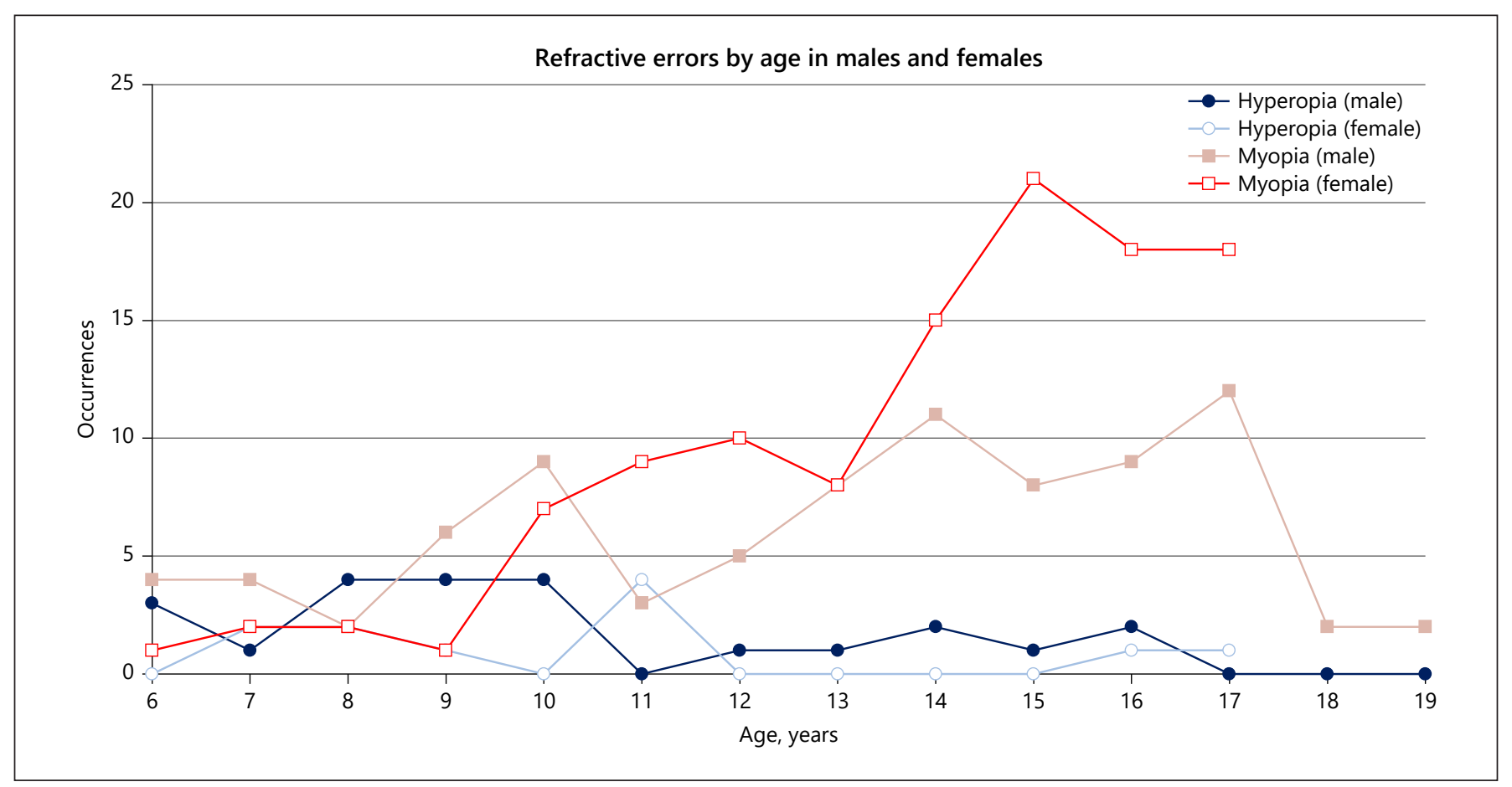

Fig. 1. Frequency distribution of refractive errors by age in males $(N=177)$ and females $(N=156)$.

Table 3. Distribution of amblyopia, low vision, and blindness by gender and age

\begin{tabular}{llll}
\hline Abnormality & Male, $n(\%)$ & Female, $n(\%)$ & Total, $n(\%)$ \\
\hline Amblyopia & & & \\
$\quad$ Age: $6-10$ years & 9 & 5 & $14(0.85)$ \\
Age: $11-19$ years & 22 & 28 & $50(3.18)$ \\
Total amblyopia & $\mathbf{3 1}(\mathbf{1 . 9 5 )}$ & $\mathbf{3 3}(\mathbf{2 . 0 7 )}$ & $\mathbf{6 4}(\mathbf{4})$ \\
Low vision & $\mathbf{7 5}$ & $\mathbf{7 6}$ & $\mathbf{1 5 1 ( \mathbf { 9 . 5 } )}$ \\
Blindness & $\mathbf{1}$ & $\mathbf{5}$ & $\mathbf{6 ( 0 . 4 )}$ \\
\hline
\end{tabular}

All the percentages are out of 1,591 .

Looking at the uncorrected refractive errors in our study, 58\% remain uncorrected and not wearing glasses. The distribution of children with refractive errors with respect to wearing or not wearing glasses is illustrated in Table 2. It shows that $58 \%(n=197)$ of the vision impaired group $(n=340)$ did not wear glasses. In the refractive error group $(n=333)$, it was $59 \%$. This implies that majority of the children did not wear glasses during our screening or full evaluation period. When we look at the comparison of male with female regarding spectacle usage, a higher percentage of girls (58\%) than boys (30\%) wore glasses (Fig. 1).

Presence and absence for amblyopia, low vision, and blindness by gender and age groups are indicated in Table 3. It shows that boys and girls have an equal prevalence of amblyopia: 31 (1.95\%) and 32 (2.07\%), respectively. The total number of amblyopia cases detected in the study was 64 , which is $4 \%$ of the total students $(n=$ $1,591)$, and it is $19 \%(n=64)$ of the vision impaired group $(n=340)$. Considering presenting visual acuity and not the best-corrected visual acuity, we find a prevalence of $9.5 \%$ of low vision and $0.4 \%$ of blindness in the study group.

Distribution of amblyopia cases is shown in Figure 2. An increase in the presence of amblyopia was noted in children aged above 10 years, in both males and females.

\section{Discussion}

Our study found prevalence of myopia, hypermetropia, and astigmatism as $12.25,1.8$, and $6.85 \%$ respectively. When compared to the study done by Padhye et al. [13] in Maharashtra, India, where 5,021 children were studied, the prevalence of myopia, hypermetropia, and astigma- 


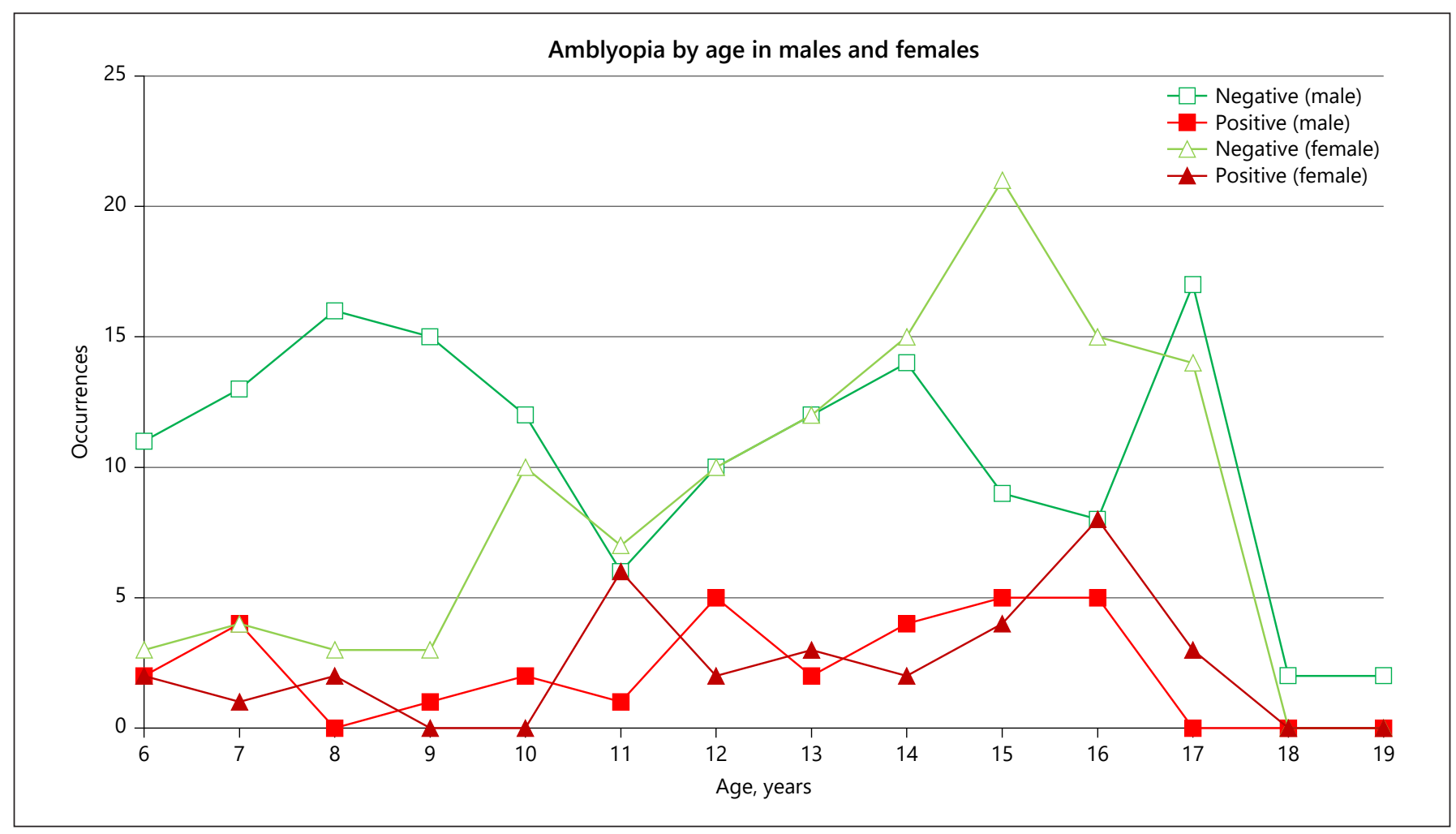

Fig. 2. Frequency distribution of amblyopia with age in males $(N=31)$ and females $(N=33)$.

tism in urban children was $3.16,1.06$, and $0.16 \%$, respectively, and $1.45,0.39$ and $0.21 \%$, respectively, in the rural group. This is lower than our results, except for the hyperopia cases.

Alsaqr et al. [14] from a population study in Saudi Arabia reported that $55.5 \%$ of the participants had some form of refractive errors, with myopia $53.3 \%$, hyperopia $2.2 \%$, and astigmatism $15 \%$ in the people with refractive errors. Only $43 \%$ of the participants had corrected refractive errors. These percentages are similar to that found in our refractive error group. This similarity may be an indication that our findings reflect the true prevalence of myopia in the gulf region.

Lin et al. [15] reported a myopic prevalence of $84 \%$ from Taiwan in the younger population by 16 years of age, which is higher than our results. Similarly, Hosaka from Japan reported an overall prevalence of 50\% [16]. Reports from Hong Kong indicate a prevalence of $36.71 \%$ for myopia, ranking first among the refractive errors [17]. These are close to our values for myopia in the refractive error group. When we consider the Western studies, Beaver Dam Study and the Baltimore Eye Survey reported the prevalence in adults to be 26.2 and $22.7 \%$, respectively, which are low when compared to our results and that of Asian countries $[18,19]$. A study among the schoolchildren in Ghana Municipality reports astigmatism ranking first with 55\%, 27\% myopia, and 18\% hyperopia [20].

The prevalence of amblyopia was reported to be $0.8 \%$ in urban and $0.2 \%$ in rural children in Maharashtra, India, as reported by Padhye et al. [13], while we found amblyopia to be $4 \%$. Looking at the literature on amblyopia from different parts of the worlds, Attebo et al. [21] reported a prevalence of 3.2\% from Sydney in people over 49 years of age causing lifelong unilateral or bilateral visual impairment.

Magdalene et al. [22] from India reported the prevalence of amblyopia to be $1.75 \%$. In that report, amblyopia was more common among males $(52.50 \%)$ than among females. Maximum number of patients were found in the age group of 11-16 (63.58\%). Rashad et al. [23] from Cairo also reported amblyopia to be $<2 \%$, that is, $1.98 \%$. Faghihi et al. [24] from Iran report from a population based study the prevalence of amblyopia was $4.6 \%$ in the total population. Hashemi et al. [25] on a meta-analysis report with the highest estimate in European Regional Office $3.67 \%$ and the lowest in African Regional Office 
$0.51 \%$. The most common cause of amblyopia was anisometropia (61.64\%). Generally, the figures for amblyopia from Iran, Australia, and Western countries cited above are similar to the findings in the study, which is around $4 \%$, indicating a higher prevalence.

In a paper on "psychosocial effects of amblyopia," the authors state that "patients with amblyopia but without strabismus reported that, amblyopia interfered with school and work to some degree and felt, it affected their lifestyle" [26]. It cannot be overemphasized that early detection of refractive errors and prompt correction are critical in the treatment of amblyopia.

An important limitation of the study is that the presence of strabismus has not been evaluated, although it is one of the most important causes of amblyopia in children. The control of blindness in children is considered a high priority within the WHO's VISION 2020 - The Right to Sight program. One of the VISION 2020 targets is to "see that all schoolchildren have a simple vision screening examination, and that glasses are provided for all who have significant refractive error. This service should be integrated with school health program" [1].

\section{Conclusion}

From our study, it can be concluded that though there is an efficient school-based screening in place with access to state-of-the-art health care facilities, uncorrected refractive errors and amblyopia among the elderly schoolchildren pose a great challenge to the policymakers in the region of Hatta, United Arab Emirates. It was found that Hatta region has a high level of refractive errors and amblyopia when compared with the literature from around the world. Myopia is found to be the most prevalent refractive error in the present study. The prevalence of 9.5\% of low vision and $0.4 \%$ of blindness in the study group constitutes the avoidable, low vision and blindness.

Comparison of the international published literature on the subject of different refractive error types shows a higher incidence of myopia, similar to our results. A significant observation is that in the 11-19 years age group school-going children, there is poor compliance of glasses usage. It constitutes more in boys (66.7\%) than in girls (35.5\%) of not wearing the glasses. This will have a major negative impact on their long-term academic performance and visual prognosis, especially if amblyopia is present.

Early detection and correction of any refractive error and treatment of amblyopia, if present, are vital for the overall development of the child. Enhancing the existing screening programs and refractive services and creating awareness among the public are all recommended. The adoption of a streamlined compliance policy for children with refractive errors is to be implemented, starting with the education of parents and teachers about their child's vision and the importance of treating refractive errors and amblyopia sooner rather than later.

\section{Acknowledgements}

We would like to acknowledge the support, guidance, and encouragement toward this project, particularly from Dr. Saif Abdulla Saeed Al Badwawi, Dr. Abdulla Naqi and Dr. Patricio Lorenzo. Special thanks go to Zahra Osman Ali for doing an efficient screening and refraction process and Renju Sebastian, for his technical support throughout the study. And finally, we would like to thank Dr. Ali Azgar Shahiwala, Dubai Pharmacy College, for his encouraging feedback on statistical analysis.

\section{Statement of Ethics}

Dubai Research and Ethics Committee's permission was obtained (DSREC-01/2015-07). In addition, permission was also obtained from the CEO of the Hatta Hospital and principals of all 4 schools. A consent form was distributed, and parents were made aware of the intended study. The World Medical Association (WMA) Declaration of Helsinki was adhered to, throughout the study period.

\section{Conflict of Interest Statement}

The authors have no conflicts of interest to disclose.

\section{Funding Sources}

The authors have no financial disclosures.

\section{Author Contributions}

All authors contributed equally.

References

1 Global initiative for the elimination of avoidable blindness. Geneva, World Health Organization, 1998 (unpublished document WHO/PBL/97.61).

2 Plan A.R. A. (n.d.). Towards Universal Eye Health. Retrieved from: http://www.wpro. who.int/entity/blindness_prevention/info/ towards_universal_eye_health_.pdf?ua $=1$. 
3 Resnikoff S, Pascolini D, Mariotti SP, Pokharel GP. Global magnitude of visual impairment caused by uncorrected refractive errors in 2004 . Bull World Health Organ. 2008;86(1):63-70.

4 Négrel AD, Minassian DC, Sayek F. Blindness and low vision in southeast Turkey. Ophthalmic Epidemiol. 1996;3(3):127-34.

5 Karande S, Kulkarni M. Poor school performance. Indian J Pediatr. 2005 Nov;72(11): 961-7.

$6 \mathrm{Wu}$ C, Hunter DG. Amblyopia: diagnostic and therapeutic options. Am J Ophthalmol. 2006;141(1),175-84.e2.

7 Bremner MH. Visual acuity in the primary school child aged four to twelve years: a review of amblyopia treatment in this age group at Princess Margaret Hospital. Austr J Opthalmol. 1984;12(4):395-9.

8 www.dsc.gov.ae/en-us. Retrieved on 2018 Sep 1.

9 International statistical classification of diseases and related health problems: Tenth revision. Geneva, World Health Organization, 1992, 456-457. Available from: https://www. who.int/occupational_health/publications/ en/oehicd10.pdf?ua=1.

10 Memon MS. Prevalence and causes of blindness in Pakistan. J Pak Med Assoc. 1992;42(8): 196-8.

11 Mansour AM, Kassak K, Chaya M, Hourani T, Sibai A, Alameddine MN. National survey of blindness and low vision in Lebanon. Br J Ophthalmol. 1997;81(10):905-6.
12 Zerihun N, Mabey D. Blindness and low vision in Jimma zone, Ethiopia: results of a population-based survey. Ophthalmic Epidemiol. 1997;4:19-26.

13 Padhye AS, Khandekar R, Dharmadhikari S, Dole K, Gogate P, Deshpande M. Prevalence of uncorrected refractive error and other eye problems among urban and rural school children. Middle East Afr J Ophthalmol. 2009 Apr;16(2):69-74.

14 Alsaqr A, Abu Sharha A, Fagehi R, Almutairi A, Alosaimi S, Almalki A, et al. The visual status of adolescents in Riyadh, Saudi Arabia: a population study. Clin Ophthalmol. 2018 May 22;12:965-72.

15 Lin LL, Chen CJ, Hung PT, Ko LS. Nationwide survey of myopia among school children in Taiwan, 1986. Acta Ophthalmol Suppl. 1988; 185:29-33.

16 Hosaka A. Population studies: myopia experience in Japan. Acta Ophthalmol Suppl. 1988; 185:37-40.

17 Fan DS, Lam DS, Lam RF, Lau JT, Chong KS, Cheung EY, et al. Prevalence, incidence, and progression of myopia of school children in Hong Kong. Invest Ophthalmol Vis Sci. 2004 Apr;45:1071-5.

18 Wang Q, Klein BE, Klein R, Moss SE. Refractive status in the Beaver Dam Eye Study. Invest Ophthalmol Vis Sci. 1994;35(13):4344-7.

19 Katz J, Tielsch JM, Sommer A. Prevalence and risk factors for refractive errors in an adult inner city population. Invest Ophthalmol Vis Sci. 1997;38(2):334-40.
20 Ovenseri-Ogbomo GO, Omuemu VO. Prevalence of refractive error among school children in the Cape Coast Municipality, Ghana. Clin Optometry. 2010:2:59-66.

21 Attebo K, Mitchell P, Cumming R, Smith W, Jolly N, Sparkes R. Prevalence and causes of amblyopia in an adult population. Ophthalmology. 1998;105(1):154-9. .

22 Magdalene D, Bhattacharjee H, Choudhury M, Multani PK, Singh A, Deshmukh S, et al. An indicator for assessment of prevalence of amblyopia. Indian J Ophthalmol. 2018 Jul; 66(7):940-4.

23 Rashad MA, Abd Elaziz KM, Fawzy SM, Abdel Latif AAM, Abdel Latif MAM. Screening of primary school children for amblyopia and amblyogenic factors in central Cairo. Egypt J Ophthalmol. 2018;22:8425319.

24 Faghihi M, Hashemi H, Nabovati P, Saatchi M, Yekta A, Rafati S, et al. The Prevalence of amblyopia and its determinants in a population-based study. Strabismus. 2017 Dec; 25(4):1-8.

25 Hashemi H, Pakzad R, Yekta A, Bostamzad P, Aghamirsalim M, Sardari S, et al. Global and regional estimates of prevalence of amblyopia: a systematic review and meta-analysis. Strabismus. 2018 Dec;26(4):168-83.

26 Packwood EA, Cruz OA, Rychwalski PJ, Keech RV. The psychosocial effects of amblyopia study. J AAPOS. 1991;3(1):15-7. 